\title{
Electrodeposition of Nanostructured Cobalt Films from Choline Chloride-Ethylene Glycol Deep Eutectic Solvent
}

\author{
G. Panzeri, ${ }^{1, *}$ L. Pedrazzetti, ${ }^{1}$ C. Rinaldi, ${ }^{2}$ L. Nobili, ${ }^{1}$ and L. Magagnin $\oplus^{1, * *, z}$ \\ ${ }^{1}$ Dipartimento di Chimica, Materiali e Ingegneria Chimica Giulio Natta, Politecnico di Milano, 20131 Milan, Italy \\ ${ }^{2}$ Dipartimento di Fisica, Politecnico di Milano, 20133 Milan, Italy
}

\begin{abstract}
Among the Deep Eutectic Solvents (DESs), ethylene glycol-based one is attracting the attention of many researchers because of its relatively low viscosity with respect to analogous eutectic systems with urea, malonic acid or glycerol. In this work, the electrochemical behavior of $\mathrm{Co}$ (II) in a eutectic solution of choline chloride and ethylene glycol (1ChCl:2EG molar ratio) was investigated by cyclic voltammetry (CV) at $70^{\circ} \mathrm{C}$ followed by galvanostatic deposition (GD). The deposits on copper substrate were characterized with a field emission scanning electron microscope (FE-SEM) showing a nanostructured surface texture with plateletlike architecture resulting in a high hydrophobicity (contact angle $\mathrm{CA}>135^{\circ}$ ). By increasing the current density, more compact films were obtained while the addition of boric acid resulted in a finer structure. X-ray diffraction (XRD) analysis determined the coexistence of FCC and HCP phases, both with and without the addition of boric acid to the bath. Annealing in a nitrogen atmosphere was performed at different temperatures $\left(300^{\circ} \mathrm{C}-600^{\circ} \mathrm{C}\right)$ to observe microstructure evolution. Magnetic properties with a coercivity of 60-80 Oe were measured by means of micro-indentation and Vibrating Sample Magnetometer (VSM).

(C) The Author(s) 2018. Published by ECS. This is an open access article distributed under the terms of the Creative Commons Attribution 4.0 License (CC BY, http://creativecommons.org/licenses/by/4.0/), which permits unrestricted reuse of the work in any medium, provided the original work is properly cited. [DOI: 10.1149/2.0031813jes]

(cc) BY
\end{abstract}

Manuscript submitted July 9, 2018; revised manuscript received August 9, 2018. Published September 11, 2018.

The interest toward cobalt and cobalt alloys relies on the variety of applications covered by this class of materials. Their applicability ranges from microelectronics, where hard magnetic Co-based alloys show properties suitable for magnetic recording. ${ }^{1-5}$ In this view, the synthesis of cobalt nanostructures has being investigated for the enhanced performances ${ }^{6,7}$ and to address self-cleaning properties with improved corrosion due to induced hydrophobicity. ${ }^{8,9}$ Electrodeposition is a well consolidated fabrication method for cobalt films; however, plating of pure cobalt from aqueous solution is not trivial due to the possible formation of hydroxides. In this view, the employment of non-aqueous solutions may represent a good alternative to the traditional baths. ${ }^{10-13}$ Eliminating or reducing the amount of water in the bath avoids oxides/hydroxide formation and allows carrying out electrodeposition at high faradaic efficiency. ${ }^{14}$ Carlin et al. ${ }^{15}$ and Mitchell et al. ${ }^{16}$ firstly studied Co electrodeposition from chloroaluminate ionic liquid, opening to a series of works based on similar systems. ${ }^{17-19}$ With the development of Deep Eutectic Solvents (DESs) by Abbott et al., ${ }^{11,13}$ different research groups investigated the suitability of these eutectic mixtures for the electrodeposition of Co-based alloys. ${ }^{20-27}$ Only recently Li et al. ${ }^{14}$ published a fundamental study on the electrodeposition of pure cobalt from urea-choline chloride melt. They defined the irreversibility of the reduction process and the diffusion coefficient of $\mathrm{Co}$ (II) ions in the solution at $100^{\circ} \mathrm{C}$. In their work, they successfully electrodeposited pure cobalt films with a maximum faradaic efficiency of about $80 \%$. In the present work, an ethylene glycol (EG) based DES was investigated because of the many advantages over the urea-based one because of its better physical properties. Abbott et al. ${ }^{28}$ reported indeed a much higher conductivity of $1 \mathrm{ChCl}: 2 \mathrm{EG}$ than $1 \mathrm{ChCl}: 2 \mathrm{U}$ which suggests that the electrodeposition process may be carried out at higher current and lower energy consumption, reducing the gap with the traditional aqueous solutions.

\section{Experimental}

Choline chloride $\left[\mathrm{HOC}_{2} \mathrm{H}_{4}(\mathrm{Cl}) \mathrm{N}\left(\mathrm{CH}_{3}\right)_{3}\right]$ (Sigma Aldrich $>99.8 \%$ ), was dried under vacuum at $120^{\circ} \mathrm{C}$ for more than 12 hours and subsequently mixed with ethylene glycol $\left[\mathrm{C}_{2} \mathrm{H}_{6} \mathrm{O}_{2}\right]$ (Sigma Aldrich $99.8 \%$ ), in the molar ratio $1 \mathrm{ChCl}: 2 \mathrm{EG}$. The solution was kept under stirring at $70^{\circ} \mathrm{C}$ until a colorless liquid was obtained. Cobalt chloride $\left[\mathrm{CoCl}_{2} \cdot 6 \mathrm{H}_{2} \mathrm{O}\right]$ was added in relatively high concentration $(0.5 \mathrm{M})$, and the effect of $0.05 \mathrm{M}$ boric acid $\left[\mathrm{H}_{3} \mathrm{BO}_{3}\right]$

\footnotetext{
*Electrochemical Society Student Member.

**Electrochemical Society Member.

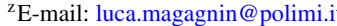

was evaluated. The electrochemical characterization was carried out in a conventional three-electrode cell using an AMEL2550 potentiostat/galvanostat. Working, counter and pseudo-reference electrodes consisted of a platinum wire; the working electrode surface was $0.13 \mathrm{~cm}^{2}$. Before every experiment, all electrodes were cleaned in a mixture of nitric acid and hydrochloric acid in 1:3 molar ratio. Galvanostatic electrodepositions were carried out on copper substrate previously etched with $5 \mathrm{wt} \%$ hydrochloric acid solution. After deposition, the samples were washed thoroughly with acetone and water. X-ray diffraction spectra were collected by a Philips PW1830 instrument using $\mathrm{Cu} \mathrm{K} \mathrm{K}_{\alpha 1}$ radiation ( $\lambda=1.54058 \AA$ ). Both as-deposited and annealed samples were examined for evaluating the microstructure. Isothermal annealing treatments were performed in a nitrogen atmosphere for 3 hours, at temperatures ranging from $300^{\circ} \mathrm{C}$ to $600^{\circ} \mathrm{C}$. Film morphology and composition were determined by scanning electron microscopy (SEM) and energy dispersive X-ray spectroscopy (EDS). Magnetic characterization was carried out by means of a Vibrating Sample Magnetometer (VSM, model EZ9 by MicroSense LLC).

\section{Results and Discussion}

Cyclic voltammetry of $1 \mathrm{ChCl}$ :2EG mixture showed a wide electrochemical window of about $2.2 \mathrm{~V}$ at $70^{\circ} \mathrm{C}$ (scan rate $25 \mathrm{mV} \mathrm{s}^{-1}$ ) on Pt substrate (Fig. 1). Within this potential interval, no significant interaction with the solvent was observed. For potential values outside this window, decomposition of both the eutectic mixture and water present in the solution was expected. Even though choline chloride was dried prior to mixing, the hygroscopic nature of the DES suggests that a small amount of water $(<1 \mathrm{wt} \%)$ was still present in the bath. ${ }^{29}$ Potential scan toward negative values caused hydrogen evolution to occur at the Pt surface below $-1.4 \mathrm{~V}$ vs Pt, where a steep decrease in the current was observed in the voltammogram. On the other hand, the anodic limit was observed at $0.7 \mathrm{~V}$ vs Pt where oxygen evolution started to take place at the working electrode surface (Fig. 1). The electrochemical behavior of the plating solution, containing $0.5 \mathrm{M} \mathrm{CoCl}_{2} \cdot 6 \mathrm{H}_{2} \mathrm{O}$, was evaluated in the same experimental conditions. Cobalt reduction at the platinum surface was revealed by the steep increase in the current density occurring around $-0.9 \mathrm{~V}$ vs $\mathrm{Pt}$ and the subsequent reduction peak at $-1.15 \mathrm{~V}$ vs Pt (Fig. 1). The existence of a cobalt deposit was confirmed by EDS analysis on the working electrode surface after potentiostatic deposition runs in the potential range of -0.9 to $-1.15 \mathrm{~V}$ vs Pt. During the reversal sweep, the corresponding anodic peak was observed around $-0.15 \mathrm{~V}$ vs Pt, where the cobalt film formed during the forward scan was stripped 


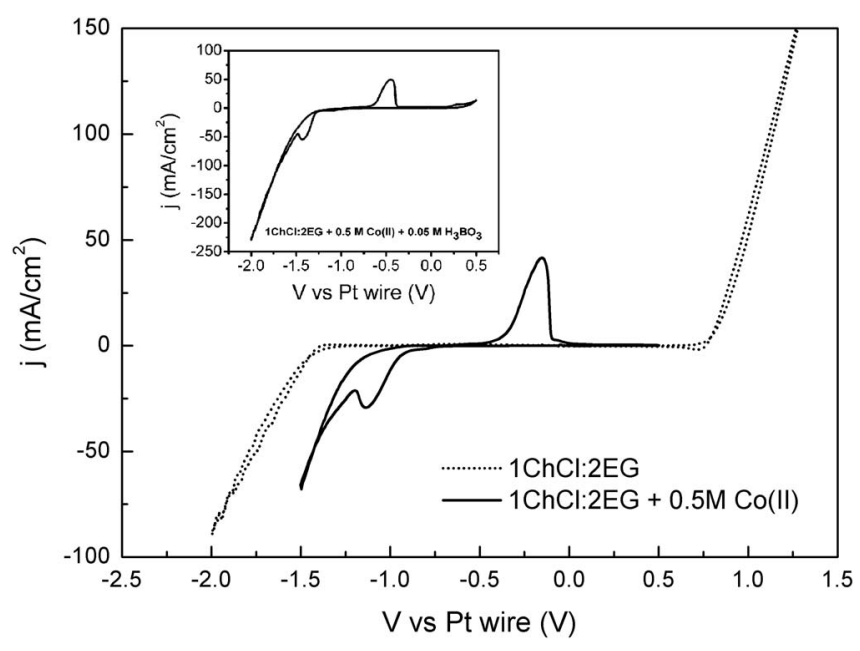

Figure 1. Cyclic voltammetry of $1 \mathrm{ChCl}: 2 \mathrm{EG}$ solution with no metal salts and with the addition of $0.5 \mathrm{M} \mathrm{CoCl}_{2} \cdot 6 \mathrm{H}_{2} \mathrm{O}\left[25 \mathrm{mV} \mathrm{s}^{-1}, 70^{\circ} \mathrm{C}\right.$, Pt substrate]. Cyclic voltammetry with the addition of $0.05 \mathrm{M}$ boric acid is also shown.

from the Pt surface. The distance between anodic and cathodic peaks was $\sim 1 \mathrm{~V}$ indicating the irreversibility of the electrodeposition process, also observed for the $1 \mathrm{ChCl}: 2 \mathrm{U}$ deep eutectic solvent by $\mathrm{Li}$ et al. ${ }^{14}$ The addition of $0.05 \mathrm{M}$ of boric acid resulted in a cathodic shift of the reduction peak which can be attributed to the complexation of cobalt ions; absorption effects at the working electrode may also play a role..$^{30-31}$ On the other hand, the higher cathodic currents were attributed to the addition of $\mathrm{H}^{+}$species to the solution. Cathodic current efficiency $(\eta)$ was calculated for the galvanostatic depositions carried out at $-5 \mathrm{~mA} / \mathrm{cm}^{2}$ on copper substrate through gravimetric approach. Cobalt deposit weight and the total charge were measured, Faraday's law was then applied. In the cobalt solution with no additive, the reduction process occurred with efficiency higher than $80 \%$, while with the addition of boric acid, the faradaic efficiencies were lower than $70 \%$, probably due to the higher concentration of $\mathrm{H}^{+}$in the bath; hydrogen reduction reaction $\left(2 \mathrm{H}^{+}+2 \mathrm{e}^{-} \longrightarrow \mathrm{H}_{2}\right)$ was thus more significant, changing the surface morphology (Figs. 2-3). On the other hand, boric acid acted against the formation of powdery deposits that may result from long-lasting electrodeposition experiments with no agitation, where hydrogen evolution at the cathode could lead to a local increase of the $\mathrm{OH}^{-}$concentration. The deposits showed a nanostructured morphology with platelet-like features randomly distributed all over the sample surface (Figs. 2-4). Each platelet displayed a significant shape anisotropy with a thickness around $50 \mathrm{~nm}$. Even though such morphology may be induced by the relatively high viscosity of the plating solution and the related hydrodynamic condition, current density also played a role. At $-20 \mathrm{~mA} / \mathrm{cm}^{2}$, cobalt films became more compact and exhibited a smaller texture, as confirmed by the visual inspection of the cobalt films, whose color turned from dark to light gray as the current density increased in modulus (Figs. $2-4)$; increasing the deposition current density, a more compact and
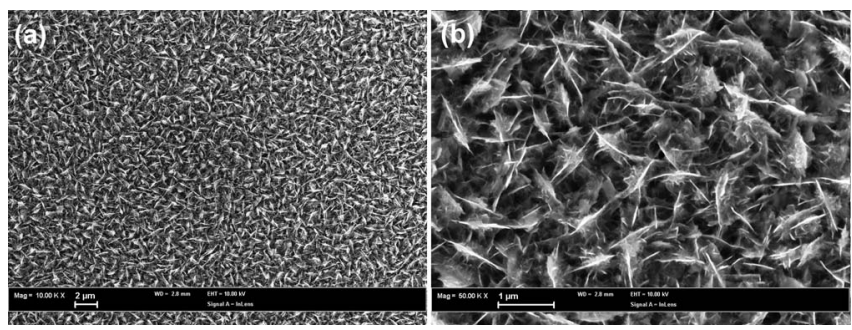

Figure 2. SEM micrograph of Co film electrodeposited from $1 \mathrm{ChCl}$ :2EG with $0.5 \mathrm{M} \mathrm{Co}(\mathrm{II})$ at $-5 \mathrm{~mA} / \mathrm{cm}^{2}, \mathrm{t}=45 \min \left[70^{\circ} \mathrm{C}\right.$, gentle stirring, $\mathrm{Cu}$ substrate]. (a) $\mathrm{Mag}=10 \mathrm{kX}$. (b) $\mathrm{Mag}=50 \mathrm{kX}$
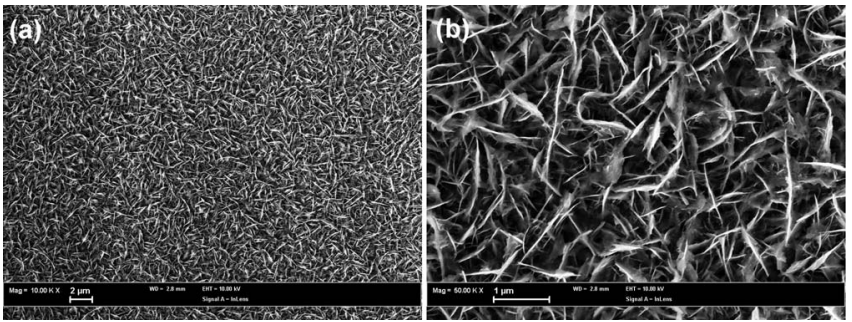

Figure 3. SEM micrograph of Co film electrodeposited from $1 \mathrm{ChCl}$ :2EG with $0.5 \mathrm{M} \mathrm{Co}(\mathrm{II})+0.05 \mathrm{M} \mathrm{H}_{3} \mathrm{BO}_{3}$ at $-5 \mathrm{~mA} / \mathrm{cm}^{2}, \mathrm{t}=45 \mathrm{~min}\left[70^{\circ} \mathrm{C}\right.$, gentle stirring, $\mathrm{Cu}$ substrate]. (a) $\mathrm{Mag}=10 \mathrm{kX}$. (b) $\mathrm{Mag}=50 \mathrm{kX}$.

less opened structure was expected following the trend showed in the SEM micrograph. The platelet-like morphology with nanometric features provided a good hydrophobicity (Fig. 5), where a finer structure, achieved with relatively low current density and with the addition of boric acid, resulted in the highest contact angle values $\left(\mathrm{CA} \sim 138^{\circ}\right.$ ). The possibility to tailor the surface morphology in order to obtain a highly hydrophobic metallic surface has been already reported from a DES in the case of nickel. ${ }^{32}$ EDS analyses detected a Co deposit with a relatively low presence of oxygen (2-4 wt \%), probably due to the sample exposure to atmosphere prior analysis; no traces of chlorine were observed. Considering the obtained structure, it was important to clean properly the samples after electrodeposition because residual solution trapped in the film could result in its oxidation. Cobalt films purity was confirmed also by X-Ray diffraction analysis, where no cobalt oxides/hydroxides reflection peaks were observed (Fig. 6). For XRD, Co films thickness of approximately $8 \mu \mathrm{m}\left(\mathrm{A}=1.5 \times 1.5 \mathrm{~cm}^{2}\right)$ was employed to avoid reflection peaks from the substrate. Nevertheless, the spectra displayed low-intensity and noisy peaks, probably because of film irregular open structure and small characteristic size of its platelets $(\sim 10 \mathrm{~nm})$. In Fig. 6, XRD pattern of the as the deposited film showed reflection peaks belonging to Co only, in particular both to the cubic (FCC) and hexagonal (HCP) phases. This conclusion was based on the presence of peaks belonging to one phase only, for example FCC (200) reflection at $2 \theta=51.52^{\circ}$, and HCP diffraction lines at $2 \theta=41.68^{\circ}$ and $2 \theta=47.56^{\circ}$ given by planes (100) and (101), respectively. The XRD spectrum showed relatively broad lines with a noisy signal and the identification of the major peak was not straightforward, the diffraction angles of FCC (111) and HCP (002) planes were indeed very similar to each other, i.e. $2 \theta=44.21^{\circ}$ and $2 \theta=$ $44.76^{\circ}$ respectively. Deconvolution analysis revealed that the major peak consisted of a single line, which was assigned to FCC (111) reflection. No differences in the microstructure were observed for the as deposited film after adding boric acid to the solution. Annealing in nitrogen atmosphere ( 3 hours) showed that the phase composition varied according to the treatment temperature in the range of $300^{\circ} \mathrm{C}$ to $600^{\circ} \mathrm{C}$. Cobalt undergoes an allotropic transformation at $422^{\circ} \mathrm{C}$, the FCC phase being stable above this temperature and the $\mathrm{HCP}$ one below it. Consequently, FCC phase is expected to grow in the electrodeposited films at the expense of the HCP one above the transition temperature and the opposite should occur below it. Actually, no change in the XRD spectrum was observed up to $400^{\circ} \mathrm{C}$ (Fig. 7),
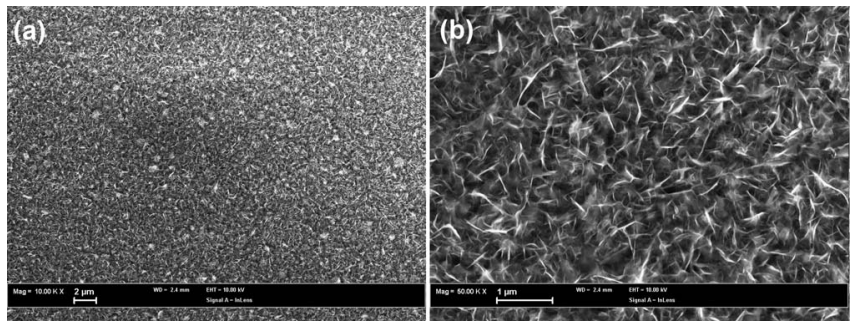

Figure 4. SEM micrograph of Co film electrodeposited from $1 \mathrm{ChCl}$ :2EG with $0.5 \mathrm{M} \mathrm{Co}(\mathrm{II})$ at $-20 \mathrm{~mA} / \mathrm{cm}^{2}, \mathrm{t}=15 \mathrm{~min}\left[70^{\circ} \mathrm{C}\right.$, gentle stirring, Cu substrate]. (a) $\mathrm{Mag}=10 \mathrm{kX}$. (b) $\mathrm{Mag}=50 \mathrm{kX}$. 
(a)

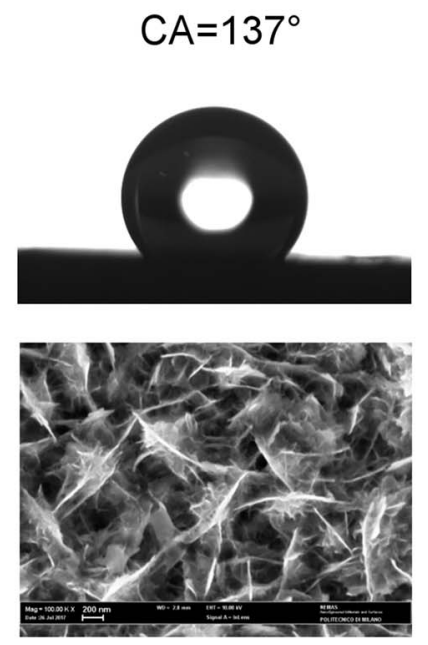

(b)

$\mathrm{CA}=139^{\circ}$
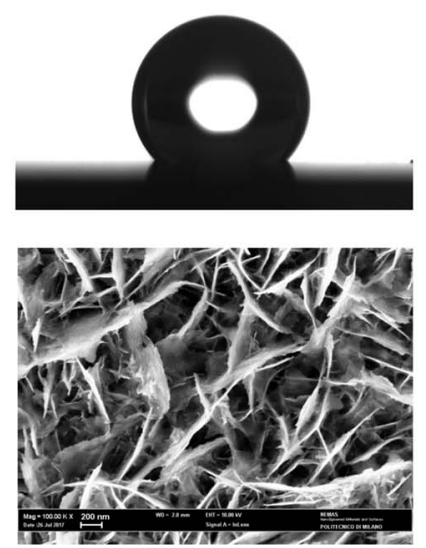

(c)
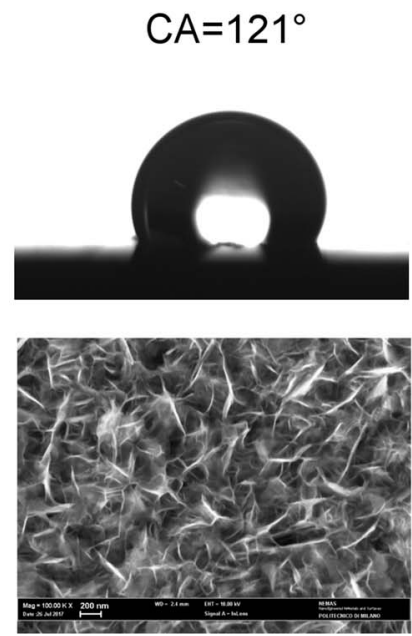

Figure 5. Contact angle measurements on Co films electrodeposited from $1 \mathrm{ChCl}: 2 \mathrm{EG}$ (a) $0.5 \mathrm{M} \mathrm{Co}$ (II) at $-5 \mathrm{~mA} / \mathrm{cm}^{2}$. (b) $0.5 \mathrm{M} \mathrm{Co}$ (II) $+0.05 \mathrm{M} \mathrm{H} \mathrm{H}_{3} \mathrm{BO}$ at $-5 \mathrm{~mA} / \mathrm{cm}^{2}$. (c) $0.5 \mathrm{M} \mathrm{Co}(\mathrm{II})$ at $-20 \mathrm{~mA} / \mathrm{cm}^{2}$. SEM micrograph Mag: $1000 \mathrm{kX}$.

whereas FCC reflections of planes (111) and (200) increased in intensity and $\mathrm{HCP}$ peaks weakened after annealing at $500^{\circ} \mathrm{C}$. This effect became even more evident at higher annealing temperature $\left(600^{\circ} \mathrm{C}\right)$, where the FCC peaks attained high intensities. Despite the thermodynamic predictions, growth of HCP phase during annealing below the transition temperature $\left(422^{\circ} \mathrm{C}\right)$ was not revealed by XRD analysis, presumably because the transformation was kinetically inhibited at so low temperatures. Annealing at $600^{\circ} \mathrm{C}$ provided an XRD pattern with high signal-to-noise ratio allowing to evaluate precisely the full width at half maximum (FWHM) of the major peak. An average crystallite size around $25-30 \mathrm{~nm}$ was estimated from the peak width according to the Debye-Scherrer equation. ${ }^{33}$ The major diffraction peak position did not shift during the heat-treatment, confirming the results obtained by the peak deconvolution. A peak shift toward smaller $2 \theta$ values would have been observed in case of HCP (002) reflection. The magnetic properties of electrodeposited cobalt films were studied by vibrating sample magnetometry (VSM); hysteresis loops were acquired along the in-plane $\left(\mathrm{H}_{/ /}\right)$and out-of-plane $\left(\mathrm{H}_{\perp}\right)$, respectively in the film plane and along the orthogonal direction. As shown in Fig. 8, cobalt films presented in-plane easy axis, with a squared loop

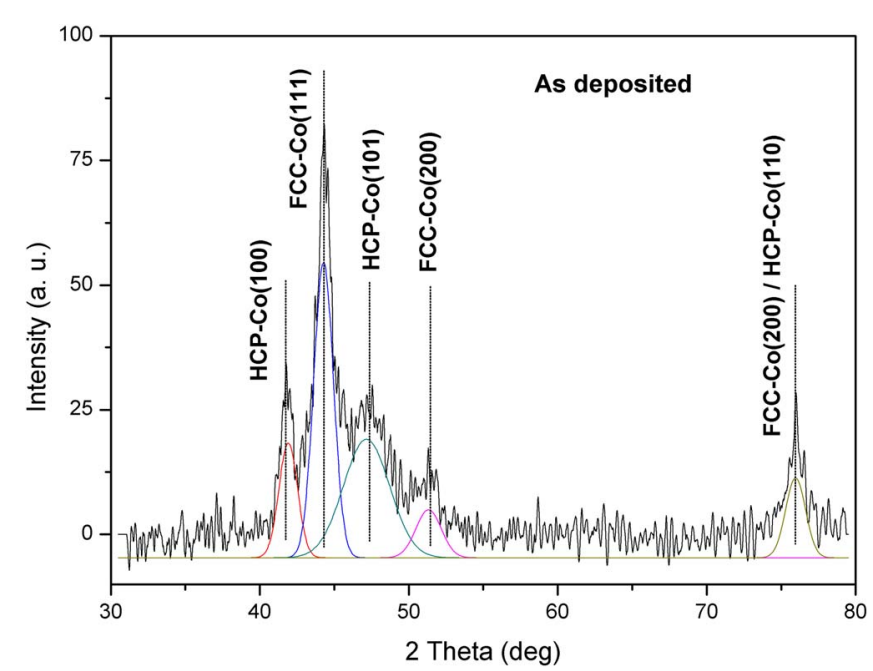

Figure 6. XRD spectrum of Co film electrodeposited from $1 \mathrm{ChCl}$ :2EG with $0.5 \mathrm{M} \mathrm{Co}$ (II) at $-5 \mathrm{~mA} / \mathrm{cm}^{2}\left[70^{\circ} \mathrm{C}\right.$, gentle stirring].
(65-70\% of remanence) and a relatively low coercivity $(4.8-6.4 \mathrm{kA} / \mathrm{m}$, i.e. $60-80 \mathrm{Oe}$ ). The out-of-plane direction was essentially the hard axis, in agreement with the shape anisotropy of the film, while the in-plane magnetic properties was verified to be isotropic (data not shown) as expected from the polycrystalline and morphological nature of the film. The reported values are typical of cobalt films; the results matched with those obtained in a previous study using the same DES and chloride salts. ${ }^{24}$ No specific magnetic behavior due to the nanostructured nature of the film, essentially isotropic, and no improvement in the coercivity field were observed.

\section{Conclusions}

Electrochemical behavior of $\mathrm{Co}(\mathrm{II})$ solution of $1 \mathrm{ChCl}$ :2EG was assessed by means of cyclic voltammetry on a platinum substrate showing cathodic and anodic peaks corresponding respectively to Co reduction and stripping of the corresponding film. The suitability of the DES for cobalt plating was then verified by performing galvanostatic deposition on copper. SEM analysis showed a nanostructured film with an irregular platelet-like surface texture showing a good

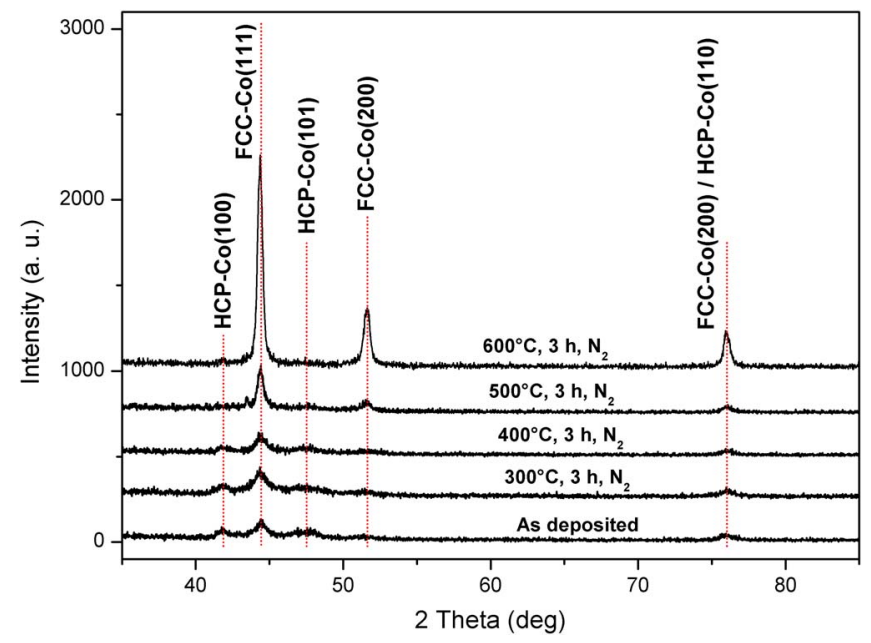

Figure 7. XRD spectra of Co film electrodeposited from $1 \mathrm{ChCl}: 2 \mathrm{EG}$ with $0.5 \mathrm{M} \mathrm{Co}$ (II) at the different annealing temperatures. Annealing was carried out in nitrogen atmosphere for $3 \mathrm{~h}$. 
a)

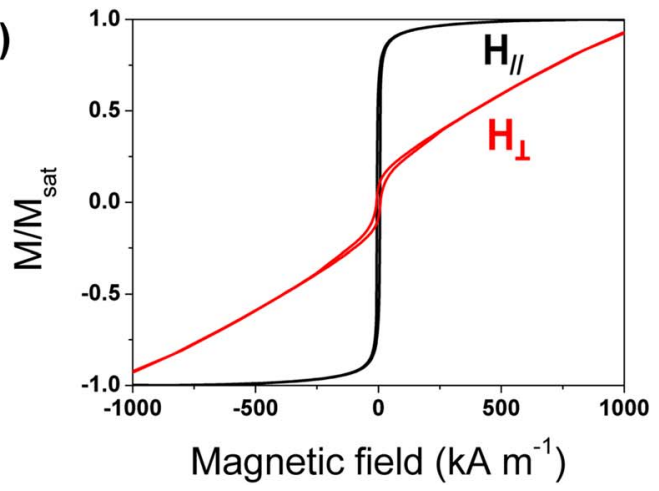

b)

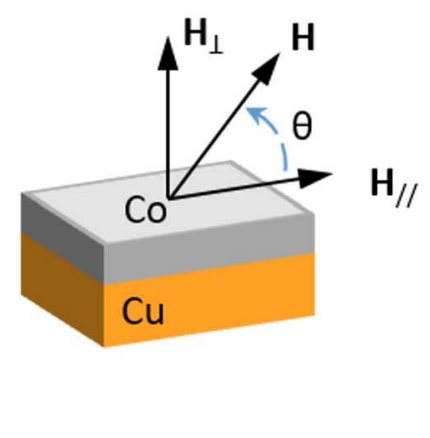

c)

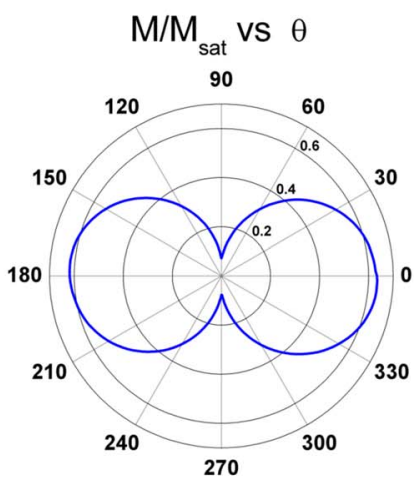

Figure 8. Hysteresis loops of cobalt films deposited from $0.5 \mathrm{M} \mathrm{Co}(\mathrm{II})+0.05 \mathrm{M} \mathrm{H}_{3} \mathrm{BO}_{3}$ at $-5 \mathrm{~mA} / \mathrm{cm}^{2}$. (b) Sketch of the magnetic field directions. (c) Squareness of the hysteresis loop versus the angle $\theta$ between the film surface and the applied magnetic field.

hydrophobicity $\left(\mathrm{CA}>135^{\circ}\right)$. By adding boric acid to the bath, a smaller and more open texture was obtained, while the cathodic current density increased in modulus from $5 \mathrm{~mA} / \mathrm{cm}^{2}$ to $20 \mathrm{~mA} / \mathrm{cm}^{2}$ resulted in a more compact film. For investigated conditions, XRD spectra of the as-deposited films showed the coexistence of FCC and HCP phases with the prevalence of the former one. Annealing in a nitrogen atmosphere at different temperatures was studied, showing the progressive transformation of the HCP phase into FCC one as the annealing temperature increased. After annealing for $3 \mathrm{~h}$ at $600^{\circ} \mathrm{C}$, only FCC peaks were observed corresponding to an average crystallite size of about $30 \mathrm{~nm}$. Mechanical characterization supported the results obtained by EDS and XRD with a microhardness of $284 \pm 20 \mathrm{HV}$ at $20 \mathrm{mN}$. Films coercivity of $4.8-6.4 \mathrm{kA} / \mathrm{m}$ (60-80 Oe) was obtained, in agreement with the typical values reported for cobalt films.

\section{ORCID}

L. Magagnin (1) https://orcid.org/0000-0001-5553-6441

\section{References}

1. G. Pattanaik, D. M. Kirkwood, X. Xu, and G. Zangari, Electrochim. Acta, 52, 8 (2007).

2. T. Chin, J. Magn. and Magn. Mater, 209, 1 (2000).

3. T. Oikawa, M. Nakamura, H. Uwazumi, T. Shimatsu, H. Muraoka, and Y. Nakamura, IEEE Trans. Magn., 38, 5 (2002).

4. P. Kelly, K. O'Grady, P. Mayo, and R. Chantrell, IEEE Trans. Magn., 25, 5 (1989).

5. K. R. Coffey, M. A. Parker, and J. K. Howard, IEEE Trans. Magn., 31, 6 (1995).

6. C. Jiang, L. Wang, and K. Kuwabara, J. Solid State Chemistry, 180, 11 (2007).

7. X. M. Liu, W. L. Gao, S. B. Miao, and B. M. Ji, J. Ph. Chem. Solids, 69, 11 (2008).
8. R. Qiu, D. Zhang, P. Wang, X. L. Zhang, and Y. S. Kang, Electrochim. Acta, 58, 699 (2011).

9. H. Xiao, A. Hu, T. Hang, and M. Li, App. Surf. Science, 324, 319 (2015).

10. T. Welton, Chem. Rev., 99, 8 (1999).

11. A. P. Abbott and K. J. McKenzie, Phys. Chem. Chem. Phys., 8, 37 (2006)

12. E. L. Smith, A. P. Abbott, and K. S. Ryder, Chem. Rev., 114, 21 (2014).

13. R. Bernasconi, G. Panzeri, A. Accogli, F. Liberale, L. Nobili, and L. Magagnin, In: Progress and Developments in Ionic Liquids, InTech (2017).

14. M. Li, Z. Wang, and R. G. Reddy, Electrochim. Acta., 123 (2014).

15. R. T. Carlin, P. C. Trulove, and C. Hugh, J. Electrochem. Soc., 143, 9 (1996).

16. J. A. Mitchell, W. R. Pitner, C. L. Hussey, and G. R. Stafford, J. Electrochem. Soc., 143, 11 (1996).

17. C. Su, M. An, P. Yang, H. Gu, and X. Guo, Appl. Surf. Sci., 256, 16 (2010).

18. R. Fukui, Y. Katayama, and T. Miura, Electrochim. Acta., 56, 3 (2011).

19. R. T. Carlin, C. Hugh, J. Fuller, and P. C. Trulove, J. Electrochem. Soc., 145, 5 (1998)

20. E. Gómez, P. Cojocaru, L. Magagnin, and E. Valles, J. Electroanal. Chem., 658, 1 (2011).

21. P. Cojocaru, L. Magagnin, E. Gomez, and E. Valles, Mater. Lett., 65, 23 (2011).

22. P. Guillamat, M. Cortés, E. Vallés, and E. Gómez, Surface and Coatings Technology, 206, 21 (2012).

23. G. Panzeri and L. Magagnin, ECS Transactions, 75, 2 (2016).

24. G. Panzeri, M. Tresoldi, C. Rinaldi, and L. Magagnin, J. Electrochem. Soc., 164, 13 (2017).

25. Y. You, C. Gu, X. Wang, and J. Tu, Surface and Coatings Technology, 206, 17 (2012).

26. J. Vijayakumar, S. Mohan, S. A. Kumar, S. Suseendiran, and S. Pavithra, Int. J. Hydrogen Energy, 38, 25 (2013).

27. G. Saravanan and S. Mohan, J. Alloys and Compounds, 522 (2012)

28. A. P. Abbott, R. C. Harris, and K. S. Ryder, J. Phys. Chem. B, 111, 18 (2007).

29. C. Du, B. Zhao, X. B. Chen, N. Birbilis, and H. Yang, Scientific reports, 6, 29225 (2016).

30. C. Karwas and T. Hepel, J. Electrochem. Soc., 136(6) (1989).

31. S. S. Abd El-Rehim, S. M. Abd El-Wahab, S. M. Rashwan, and Z. M. Anwar, J. Chem. Technol. Biotechnol., 75(3) (2000).

32. C. Gu and J. Tu, Langmuir, 27, 16 (2011).

33. B. D. Cullity and S. R. Stock, Elements of X-ray Diffraction, Pearson Education (2014). 